\title{
Performance Evaluation of LEED-certified Affordable Homes: Case Study of LEED-certified Habitat for Humanity
}

\author{
Eunsil Lee ${ }^{1}$ \\ ${ }^{1}$ School of Planning, Design and Construction, Michigan State University, USA \\ Correspondence: Eunsil Lee, School of Planning, Design and Construction, Michigan State University, 552 West \\ Circle Dr., East Lansing, MI 48824, USA. Tel: 1-517-432-3249. E-mail: leeeunsi@msu.edu
}

Received: November 26, 2018

doi:10.5539/jsd.v12n1p120

\author{
Accepted: December 24, 2018 Online Published: January 31, 2019 \\ URL: https://doi.org/10.5539/jsd.v12n1p120
}

\begin{abstract}
Despite the rapid growth in the number of LEED-certified homes, little data is currently available about the actual effects of LEED-certified affordable homes. The purpose of present study is to conduct a comprehensive performance evaluation for LEED-certified Habitat for Humanity residences in terms of (1) energy efficiency, (2) indoor environmental quality, (3) health impact, (4) residential satisfaction, (5) quality of life, and (6) environmental attitudes and behaviors. A case study was conducted with 15 households living in LEED-certified Habitat for Humanity homes in Kent County, Michigan using observation, in-depth interviews, and surveys. Findings revealed overall housing satisfaction was very high although some residents indicated lower satisfaction with their neighborhood. Most of case study homes had 30-50\% lower electricity and natural gas bills. Most participants were satisfied with indoor environmental quality (IEQ) including thermal comfort, indoor air quality, amount daylight, quality of artificial lighting, and acoustical condition. Most participants agreed that since moving into their current homes they have experienced improved family relationships, better health conditions, more positive attitudes, and better performance of their children. The major findings of this case study support the positive effects of LEED-certified low-income homes on residents' behavioral, social, and psychological aspects of well-being.
\end{abstract}

Keywords: LEED-certified Habitat for Humanity, post-occupancy evaluation, energy efficiency, indoor environmental quality, health impact, quality of life

\section{Introduction}

The U.S. Green Building Council's (USGBC) Leadership in Energy and Environmental Design (LEED) is one of the leading rating and certification systems for green buildings in the world. During the past few years, there has been a rapid increase in the number of green homes that received LEED certification in the U.S. and Canada. According to LEED for Home market brief (USGBC, 2018a), the number of LEED-certified residential units jumped to more than 158,600 in 2018 from about 50,700 in 2013 (see Figure 1). The increase in the number of LEED-certified homes is expected to continue because there are tremendous numbers of units that have registered for LEED certification (USGBC, 2018a).

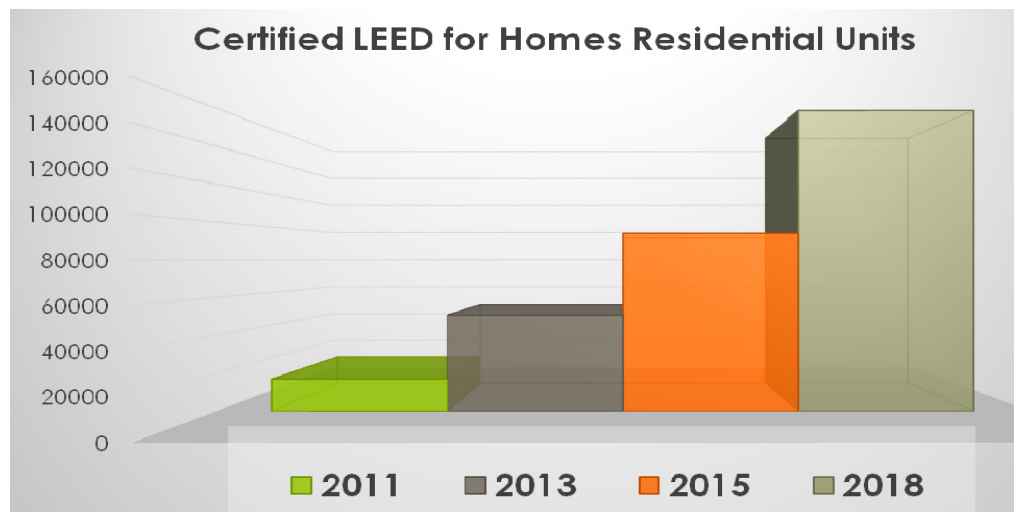

Figure 1. Increase in the number of LEED-certified homes (Source: USGBC) 
The ever-increasing number of LEED-certified homes today is largely credited to the affordable housing sector, which has been an important part of the green movement. According to 2018 LEED in Motion report (USGBC, 2018b), about 43\% of LEED for Home units were affordable housing projects. Habitat for Humanity contributed to this increasing number of affordable green homes as Habitat affiliates have built numerous energy-efficient homes since 1995 and increased participation in LEED for Home certification across the U.S. with support from various funding agencies (Habitat for Humanity, 2012).

With the huge growth in the number of green buildings, it has become increasingly easier to identify the benefits of green buildings. According to USGBC (2018c), LEED-certified buildings generally use about $25 \%$ less energy and about $11 \%$ less water, produce about $34 \%$ less $\mathrm{CO} 2$ emissions, and saved more than 80 million tons of waste. To measure the performance of LEED-certified buildings, many researchers conducted post-occupancy evaluations (POE). POE is "the process of evaluating building(s) in a systematic and rigorous manner after they have been built and occupied for some time" (Preiser, Rabinowitz, \& White, 1988, p. 3). POEs are essential to determine whether buildings and technologies function as intended, how well the buildings match user needs, and how building design, performance, and fitness for each building's purpose can be improved. As POE for green buildings can help building professionals and policymakers understand how to obtain better results from green building technologies, there have been many POEs that evaluated the performance of LEED-certified buildings, particularly for office buildings (e.g., Abbaszadeh, Zagreus, Lehrer, \& Huizenga, 2006; Altomonte \& Schiavon, 2013; GSA, 2011; Huizenga, Zagreus, Arens, \& Lehrer, 2003; Lee \& Kim, 2008; Singh, Syal, Grady, \& Korkmaz, 2010; Liang et al., 2014; Newsham et al., 2013).

However, POE is still significantly underutilized for LEED-certified residential buildings. According to a Realtor and Sustainability report from National Association of Realtors (2018), home buyers' interests in sustainability are growing and environmentally-friendly features are important factors in their home purchase decision. Despite the rapid growth in the number of LEED-certified homes as well as consumer interest in green homes, the evaluation of the actual performance of LEED-certified homes has been overlooked, and, in particular, little data is currently available about the actual effects of LEED-certified affordable homes. Considering that it remains unclear the extent to which a LEED-certified affordable home actually improves energy efficiency, provides a healthier and more comfortable environment, and improves satisfaction and quality of life while in use, the purpose of present study is to conduct a comprehensive performance evaluation for LEED-certified Habitat for Humanity residences in terms of (1) energy efficiency, (2) indoor environ quality, (3) health impact, (4) residential satisfaction, (5) quality of life, and (6) environmental attitudes and behaviors.

\subsection{LEED for Home}

The LEED-rating system consists of five overarching categories: Building Design and Construction $(\mathrm{BD}+\mathrm{C})$, Interior Design and Construction (ID+C), Building Operations and Maintenance $(\mathrm{O}+\mathrm{M})$, Neighborhood Development (ND), and Homes. The LEED for Home rating system is divided into two types of projects: (1) Homes and (2) Multifamily Midrise. The evaluation categories for LEED for Home credits include integrative process, location and transportation, sustainable sites, water efficiency, energy and atmosphere, material and resources, indoor environ quality, innovation, and regional priority (see Table 1). Among these evaluation categories, energy and atmosphere points are the highest portion of the total credits followed by indoor environmental quality. The total points possible is 110 . Depending on the points earned, one of four LEED certifications is awarded: Certified (40 to 49 points), Silver (50 to 59 points), Gold (60 to 79 points), and Platinum (80 to 110 points).

Table 1. LEED for homes points breakdown for LEED v4 for building design and construction

\begin{tabular}{lcc}
\hline \multicolumn{1}{c}{ Evaluation Categories } & Homes Project Points & Multifamily Midrise Project Points \\
\hline Integrative Process & 2 & 2 \\
Location and Transportation & 15 & 15 \\
Sustainable Sites & 7 & 7 \\
Water Efficiency & 12 & 12 \\
Energy and Atmosphere & 38 & 37 \\
Materials and Resources & 10 & 9 \\
Indoor Environ Quality & 16 & 18 \\
Innovation & 6 & 6 \\
Regional Priority & 4 & 4 \\
\hline Total & 110 & 110 \\
\hline
\end{tabular}




\subsection{Effects of LEED-certified Buildings}

\subsubsection{Energy Efficiency}

Energy efficiency is one of the well-recognized benefits of LEED-certified buildings. According to USGBC (2018c), LEED-certified buildings saved \$1.2 billion in energy costs between 2015 and 2018. Energy efficient labels such as Energy Star positively impact market sale price (Fuerst, McAllister, Nanda, \& Wyatt, 2015; USGBC, 2015; Walls, Gerarden, Palmer, \& Bak, 2017). Many studies found that energy usage of LEED-certified buildings is generally about $20 \%-30 \%$ less than conventional buildings (Fowler, Rauch, Henderson, \& Kora, 2011; Newsham, Mancini, \& Birt, 2009; Walls, 2017).

However, some studies found there is no significant energy saving in LEED-certified buildings compared with non-LEED buildings (Jeong et al., 2016; Scofield, 2013; Scofield \& Doane, 2018). According to a recent study by Scofield and Doane (2018), LEED-certified buildings in Chicago did not use less energy than their similar non-LEED counterparts. They examined the 2015 energy usage data for 1,509 properties in Chicago to compare energy use of LEED-certified offices, K-12 schools, and multifamily housing with conventional building counterparts. Their findings revealed that the energy use of LEED-certified offices and multifamily housing were not significantly lower than other offices or multifamily housing properties. LEED-certified schools used $17 \%$ more electric energy than conventional schools, although they used less natural gas energy. Jeong et al. (2016) also found there was no significant difference in energy usage between LEED-certified and non-LEED multifamily housing properties. Thus, the results about the energy-efficiency of LEED-certified buildings were inconsistent.

\subsubsection{Indoor Environmental Quality (IEQ)}

IEQ encompasses thermal comfort, indoor air quality, lighting quality, acoustics, and interior architectural features such as space layout, space size, furnishings, and interior finishes. As people spend $90 \%$ of their time indoors, IEQ is an important factor for occupants' satisfaction and well-being (Frontczak et al., 2012; Issa, Rankin, Attalla, \& Christian, 2011; Singh et al., 2010). Studies demonstrated that occupants in LEED-certified buildings were more satisfied with their IEQs than those in non-LEED buildings (Abbaszadeh, 2006; Frontczak et al., 2012: Huizenga et al., 2005). Many studies found LEED-certified buildings provide better indoor air quality (Abbaszadeh et al., 2006; Huiznega et al., 2003; Huiznega et al., 2005; Lee \& Kim, 2008; Newsham et al., 2012) and better thermal comfort (Abbaszadeh et al., 2006; Huiznega 2005; Newsham et al., 2012). On the other hand, there was lower satisfaction with the lighting quality of LEED-certified buildings when compared to conventional buildings in many studies (Altomonte \& Schiavon, 2013; Huizenga et al., 2005; Lee \& Kim, 2008). Also, the occupants' satisfaction with the acoustic conditions in LEED-certified buildings was not higher than conventional buildings (Abbaszadeh et al., 2006; Huizenga et al., 2005; Lee \& Kim, 2008).

\subsubsection{Health Impact}

The health impacts of LEED-certified buildings have not been studied extensively, but some studies found significant health impacts of LEED-certified buildings. For example, Sing et al. (2010) conducted pre- and post-move surveys for office buildings and found improved health and well-being in the LEED-certified buildings. Garland et al. (2013) found support for significant health effects of LEED-certified homes on the respiratory health including decreased respiratory and asthma symptoms in LEED-certified homes. Colton et al. (2014) measured indoor air quality of LEED and conventional public housing and found indoor air quality of LEED-certified homes was significantly better than conventional buildings. The study reported the occupants in the LEED-certified homes had $47 \%$ less sick building syndrome symptoms. However, a longitudinal study by Thatcher and Milner (2012) found that green buildings did not show better physical health or mental well-being, when comparing GreenStar-accredited buildings with conventional buildings.

\subsection{LEED-certified Habitat for Humanity}

Habitat for Humanity, a non-profit housing ministry, builds decent low-cost homes in partnership with low-income families by using volunteer labor, discounted or donated materials, and home buyer sweat equity (Habitat for Humanity, 2018). The homes are sold at cost with very low or no-interest mortgages. In 2009, Habitat for Humanity International announced its commitment to bring green housing to all income levels by way of a $\$ 30$ million grant program through a partnership with The Home Depot Foundation (Habitat for Humanity, 2011). Since then, the number of LEED-certified Habitat for Humanity homes continues to increase across the U.S. (Habitat for Humanity, 2012).

Starting in 2010, all Michigan affiliates pledged to build to at least minimum Energy Star standards (Habitat for Humanity of Michigan, 2011) and many Habitat for Humanity homes in Michigan received varying degrees of 
LEED certification (see Habitat for Humanity, 2012). The Habitat for Humanity of Kent County chapter in the Grand Rapids area built the first affordable LEED-certified home in the U.S. in 2006. Since 2007, it has built all new homes to minimum LEED silver certification (Green Home Institute, 2011). It built most of the LEED-certified Habitat homes in Michigan by completing 158 total LEED-certified Habitat for Humanity homes as of June 2017 including 1 Certified, 62 Silver, 86 Gold, and 8 Platinum (Habitat for Humanity of Kent County, 2018).

\section{Method}

A case study was conducted with residents living in LEED-certified Habitat for Humanity homes to evaluate the performance of green design and technology of LEED-certified affordable homes.

\subsection{Participants}

The case study participants were selected purposefully from the list of LEED-certified homes built by Habitat for Humanity in Kent County, Michigan. A total of 15 households living in LEED-certified Habitat homes (12 LEED Silver and 3 LEED Gold) participated. Table 2 presents the 15 case study homes' housing type, LEED ratings, number of bedrooms, and number of residents.

Table 2. List of 15 LEED-certified habitat homes for case study

\begin{tabular}{lllccc}
\hline $\begin{array}{c}\text { Case Home } \\
\text { No. }\end{array}$ & \multicolumn{1}{c}{ House type } & $\begin{array}{c}\text { LEED } \\
\text { ratings }\end{array}$ & $\begin{array}{c}\text { No. of } \\
\text { bedroom }\end{array}$ & $\begin{array}{c}\text { No. of } \\
\text { residents }\end{array}$ & $\begin{array}{c}\text { No. of } \\
\text { children }\end{array}$ \\
\hline 1 & Multifamily home & Silver & 3 & 4 & 3 \\
2 & Multifamily home & Silver & 3 & 4 & 1 \\
3 & Multifamily home & Silver & 2 & 2 & - \\
4 & Multifamily home & Silver & 2 & 4 & 2 \\
5 & Multifamily home & Silver & 2 & 1 & - \\
6 & Single family home & Gold & 3 & 4 & 2 \\
7 & Single family home & Silver & 3 & 3 & 2 \\
8 & Multifamily home & Silver & 3 & 4 & 3 \\
9 & Single family home & Silver & 3 & 4 & 2 \\
10 & Single family home & Silver & 5 & 6 & 1 \\
11 & Single family home & Gold & 3 & 2 & 3 \\
12 & Single family home & Gold & 5 & 5 & - \\
13 & Single family home & Silver & 3 & 2 & 4 \\
14 & Single family home & Silver & 4 & 5 & 1 \\
15 & Single family home & Silver & 2 & 2 & \\
\hline
\end{tabular}

\subsection{Data Collection}

To obtain the comprehensive understanding of occupants' living experiences and actual effects of green design, this study used multiple data collection methods: observation, in-depth interviews, and surveys (see Table 3).

First, this study conducted observations of physical characteristics for home environment and neighborhood conditions for each case study home. The IEQ was also measured using IEQ monitoring kits while observations were held. The photos of exterior for case study home \#1, \#2, \#6, and \#12 are presented in Figure 2.

Second, in order to examine the performance of LEED-certified Habitat homes, in-depth interviews were conducted with the residents using a semi-structured interview protocol. The interview questions were designed to elicit qualitative data about occupants' satisfaction with home environment, quality of life, IEQ, interior space, energy efficiency, and building performance as well as perceived health impact and environmental behaviors. The interview questionnaire was reviewed and approved by the Institutional Review Board of the Human Subject Protection Program. Each interview was tape-recorded and conducted at each participant's home for 60 to 90 minutes.

Third, quantitative data was collected using a self-administered survey questionnaire. The survey instrument was developed based on previous POE instruments including the survey tool from the Center for the Built Environment (CBE) at the University of California at Berkeley. The questionnaire consists of six sections: (1) general information about home, (2) satisfaction with home and neighborhood environment, (3) overall 
well-being, (4) energy efficiency, (5) environmental behaviors, and (6) demographic information. The questions asked how participants were satisfied or dissatisfied with their home environment, energy efficiency, health conditions, and well-being using a seven-point Likert scale: "1" for very dissatisfied to "7" for very satisfied.

Table 3. Data collection methods for case studies

\begin{tabular}{|c|c|}
\hline Methods & Data sources \\
\hline 1 Observation & $\begin{array}{l}\text { Photos of home attributes and neighborhood conditions } \\
\text { IEQ monitor data: Temperature, Humidity, CO2, Lighting }\end{array}$ \\
\hline 2 In-depth interview & $\begin{array}{l}\text { Interview protocol: Open-ended questions } \\
\text { - Overall satisfaction \& quality of life } \\
\text { - Comfort \& satisfaction with IEQ } \\
\text { - Feeling about space planning, furnishings, \& finishes } \\
\text { - Satisfaction with building performance \& energy efficiency } \\
\text { - } \text { Environmed health impact } \\
\text { Ental attitude \& behavior }\end{array}$ \\
\hline $3 \quad$ Survey & $\begin{array}{l}\text { Survey questionnaire } \\
\text { - General information about home } \\
\text { - Satisfaction with home and neighborhood } \\
\text { - Overall well-being \& IEQ } \\
\text { - Sverall health and well-being } \\
\text { - } \text { Envisfaction with energy efficiency } \\
\end{array}$ \\
\hline
\end{tabular}

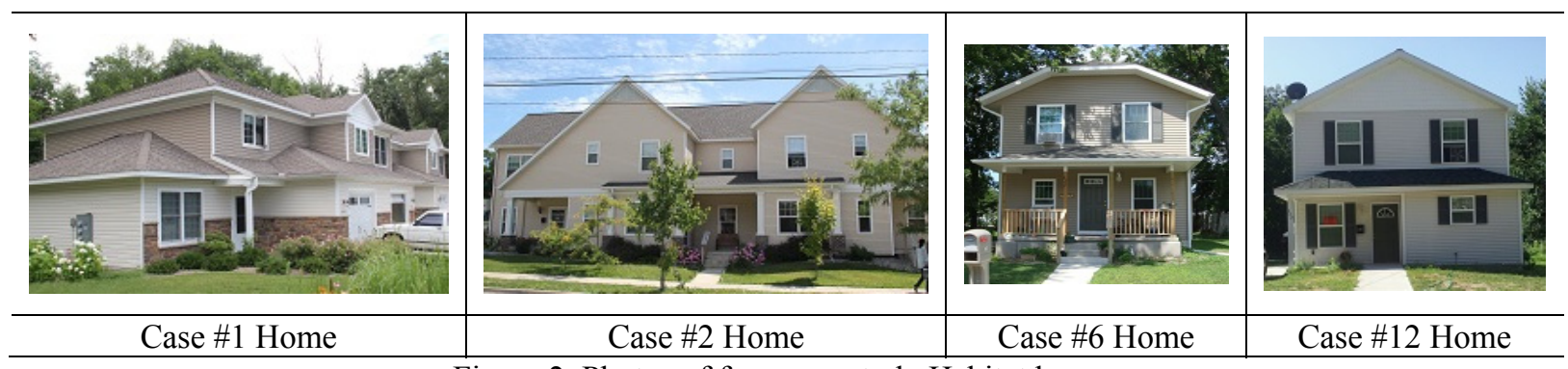

Figure 2. Photos of four case study Habitat homes

\section{Results}

\subsection{Participants Profile}

Table 4 shows the demographic information of the 15 participants. The participants consisted of 4 males and 11 females. The ages of the respondents ranged from 20 years old to 60 years old or older. About half of the respondents self-reported as Black or African-American (50.0\%), followed by White (28.6\%), others (14.3\%), and Asian (7.1\%). Nine respondents were currently employed and 4 were unemployed. About half of the respondents identified their education level as having completed high school (53.8\%). About $30.8 \%$ completed college, $7.7 \%$ completed grade school, and about $7.7 \%$ had no formal education. A majority of respondents' income ranged from "less than $\$ 20,000$ " to "not more than $\$ 40,000$ " (92.9\%). 
Table 4. Participants' demographics

\begin{tabular}{lcc}
\hline \multicolumn{1}{c}{ Demographics } & No. of respondents & Percent \\
\hline Age (N=14) & 1 & 7 \\
29 years or younger & 5 & 36 \\
$30-39$ & 4 & 29 \\
$40-49$ & 3 & 21 \\
$50-59$ & 1 & 7 \\
\hline 00 years or older & 4 & 29 \\
\hline Gender (N=15) & 11 & 71 \\
Male & & \\
Female & 4 & 29 \\
\hline Race (N=14) & 7 & 50 \\
White & 1 & 7 \\
Black or African-American & 2 & 69 \\
Asian & & 31 \\
Other (Mexican, Mixed) & 9 & 7.7 \\
\hline Employment Status (N=13) & 4 & 7.7 \\
Employed & & 53.8 \\
Other (Disabled or Social Security) & 1 & 30.8 \\
\hline Education Level (N=13) & 1 & 28.6 \\
No formal education & 7 & 64.3 \\
Completed grade school & 4 & 7.1 \\
Completed high school & & \\
Completed college & 4 & 9 \\
\hline Household Income (N=14) & 1 & \\
Less than \$20,000 & & \\
\$20,000 to \$39,999 & & \\
\$40,000 to \$59,999 & & \\
\hline & & \\
\hline
\end{tabular}

Housing characteristics for the case study homes are presented in Table 5. Out of 15 homes, 12 were Silver certified and 3 were Gold certified. Nine homes were single family housing units and 6 homes were multi-family housing units. The length of residency in the houses for all participants was not more than 5 years. Out of 15 homes, 8 homes were 3 -bedroom units and 4 homes were 2-bedroom units. Three homes were 4 - or 5 -bedroom units. The number of family members in the houses ranged from 1 to 6 . Many households had multiple children living in the house. The numbers of hours the participants spent at home daily ranged widely from 5 hours to more than 20 hours per day.

Table 5. Participant housing characteristics

\begin{tabular}{lcc}
\hline \multicolumn{1}{c}{ Demographics } & No. of respondents & Percent \\
\hline LEED rating $(\mathrm{N}=15)$ & 0 & 20 \\
Platinum & 3 & 80 \\
Gold & 12 & \\
Silver & 0 & 60 \\
Certified & & 40 \\
\hline Types of housing $(\mathrm{N}=15)$ & 9 & 13.3 \\
Single-family detached & 6 & 13.3 \\
Multi-family attached & & 33.3 \\
Length of residency $(\mathrm{N}=15)$ & 2 & 26.7 \\
Less than one year & 2 & 13.3 \\
1-1.9 years & 5 & \\
2-2.9 years & 4 & \\
3-3.9 years & 2 & \\
4 years or more & & \\
\hline
\end{tabular}




\begin{tabular}{lcc}
\hline Number of bedrooms $(\mathrm{N}=15)$ & & 26.7 \\
2 bedrooms & 4 & 53.3 \\
3 bedrooms & 8 & 6.7 \\
4 bedrooms & 1 & 13.3 \\
5 bedrooms or more & 2 & 6.7 \\
\hline Number of residents $(\mathrm{N}=15)$ & & 26.7 \\
1 person & 1 & 13.3 \\
2 people & 4 & 26.7 \\
3 people & 2 & 26.7 \\
4 people & 4 & 14.2 \\
5 people or more & 4 & 21.4 \\
\hline Number of child(ren) $(\mathrm{N}=14)$ & 21.4 \\
No child & 2 & 21.4 \\
1 child & 21.4 \\
\hline children & 3 & 2 \\
4 children & 3 & 6.7 \\
\hline children or more & 3 & 33.3 \\
5 hours or less/day & 3 & 13.3 \\
11 -15 hours/day & & 46.6 \\
\hline N-20 hours/day & 1 & 5 \\
\hline
\end{tabular}

\subsection{Energy Efficiency}

\subsubsection{Changes in Monthly Bills}

Table 6 presents the average monthly bills for the electricity and natural gas as reported by participants. The monthly electricity bills ranged from $\$ 30$ to $\$ 200$ in the summer and from $\$ 40$ to $\$ 120$ in the winter. The monthly natural gas bills ranged from $\$ 9$ to $\$ 50$ in the summer and $\$ 40$ to $\$ 120$ in the winter.

Table 6. Average monthly energy bills

\begin{tabular}{cccccccc}
\hline Case & LEED & No. of & \multirow{2}{*}{ No of residents } & \multicolumn{2}{c}{ Electricity bill (\$) } & \multicolumn{2}{c}{ Natural gas bill (\$) } \\
\cline { 3 - 7 } No. & ratings & bedroom & & Summer & Winter & Summer & Winter \\
\hline 1 & Silver & 3 & 4 & 60 & 60 & $\mathbf{9}^{*}$ & $\mathbf{4 0}^{*}$ \\
2 & Silver & 3 & 4 & $50-53$ & 48 & 32 & 100 \\
3 & Silver & 2 & 2 & - & $50-60$ & - & - \\
4 & Silver & 2 & 4 & 40 & $\mathbf{4 0 *}$ & 30 & $50-60$ \\
5 & Silver & 2 & 1 & $\mathbf{3 0}$ & $40-50$ & - & - \\
6 & Gold & 3 & 4 & $50-60$ & $50-60$ & 30 & $40-50$ \\
7 & Silver & 3 & 3 & $\mathbf{1 5 0 - 2 0 0 * *}$ & $80-100$ & $\mathbf{5 0 * *}$ & 100 \\
8 & Silver & 3 & 4 & 60 & - & $\mathbf{5 0}$ & $\mathbf{1 2 0 * *}$ \\
9 & Silver & 3 & 4 & 60 & $>60$ & $\mathbf{5 0 * *}$ & $70-80$ \\
10 & Silver & 5 & 6 & $80-120$ & $>\mathbf{8 0 - 1 2 0 * *}$ & - & - \\
11 & Gold & 3 & 2 & 51 & 52 & 23 & - \\
12 & Gold & 5 & 5 & - & - & - & - \\
13 & Silver & 3 & 2 & 100 & 75 & $25-30$ & 100 \\
14 & Silver & 4 & 5 & $80-90$ & $80-90$ & - & - \\
15 & Silver & 2 & 2 & 35 & - & - & 50 \\
\hline
\end{tabular}

* the lowest amount, ** the highest amount in each column

During the interviews, participants were asked to answer the question 'Are there any differences in the bills 
when compared to those of your previous home?' The answers varied among interviewees (see Table 7). Eight respondents indicated that they noticed cheaper energy bills in their current homes than in their previous houses. Overall, they saved about $50 \%$ maximum on their electricity costs and about $30-50 \%$ on their heating bills. One of the respondents mentioned,

\section{“Electricity went from \$100 in bills to about \$40-50, and with summer it is about \$30-40.” (Case \#4)}

However, two respondents indicated their bills were similar to the previous ones, and two respondents reported bills higher than those in previous houses. Among those four respondents, one was a 1-resident home and three had 5 or more residents. It is not surprising that a move from a small 1-bedroom apartment to a house would incur higher bills. Big families with 5 or more residents included teenaged children who took showers many times a day and used computers and video game machines for long hours each day. Energy costs are thus also related to families' lifestyles and life cycles.

Table 7. Comparisons of energy bills between pre- and post-move

\begin{tabular}{lc}
\hline \multicolumn{1}{c}{ Participants' responses } & Frequency \\
\hline Cheaper energy bills in the current home & 8 \\
No changes in energy bills & 2 \\
Higher energy bills in the current home & 2 \\
Higher electricity bills in the summer due to air conditioning & 3 \\
\hline
\end{tabular}

\subsubsection{Satisfaction with Energy Efficiency}

Figure 3 shows the occupants' perceptions about energy efficiency of the current LEED-certified Habitat for Humanity homes. Eight out of 11 respondents who answered the question about overall energy efficiency of their homes rated 6 or 7 points out of 7 , indicating "very energy efficient."

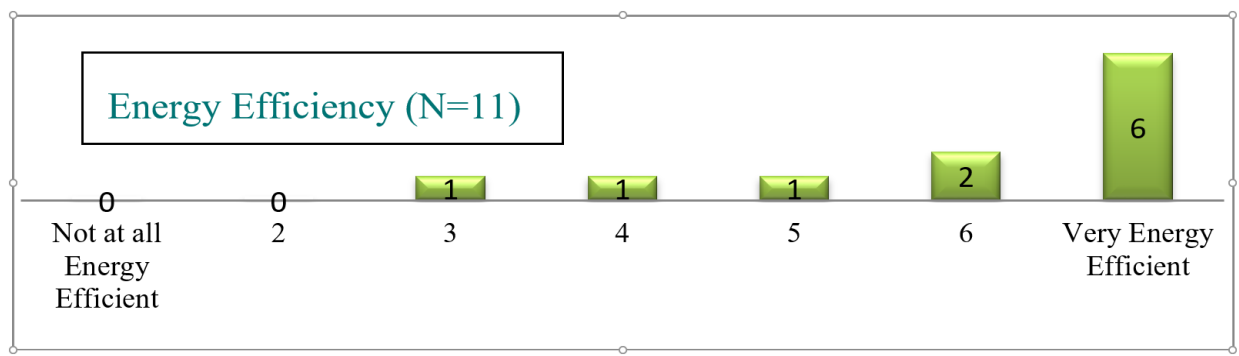

Figure 3. Perception about overall energy efficiency of green home performance

Table 8 shows participants' satisfaction with the efficiency of water $(M=5.91)$, electricity $(M=6.08)$, and natural gas $(\mathrm{M}=6.08)$. Overall satisfaction levels for the efficiency of water, electricity, and natural gas were very high. There were no negative responses for the efficiency of electricity and natural gas, though a negative response was shown in the efficiency of water. 
Table 8. Satisfaction with energy efficiency

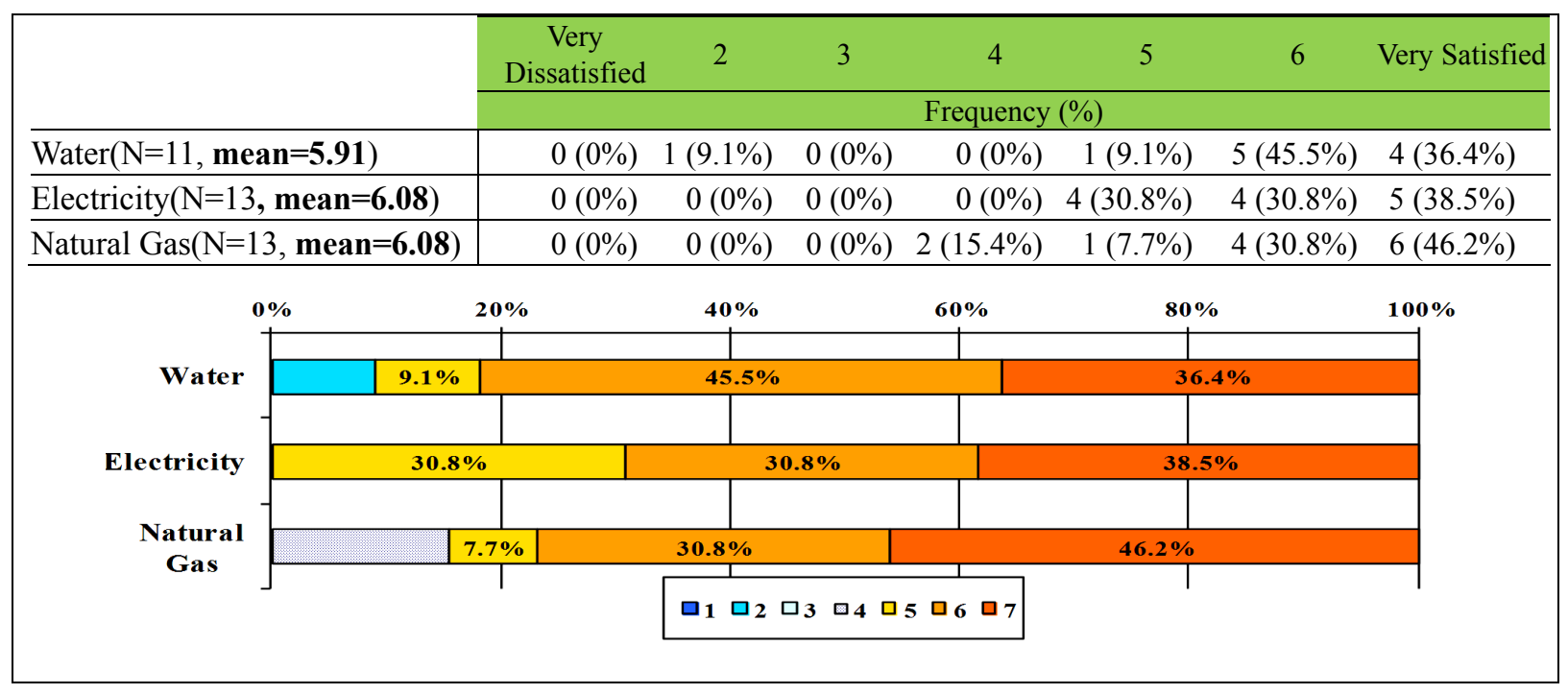

The main satisfactory features frequently mentioned by respondents included "good insulation with no breeze inside" ( $(\mathrm{n}=4)$; "efficiency of energy-saving systems and equipments such as windows, furnaces, and water heaters" ( $\mathrm{n}=7)$; "lighting system using energy-efficient bulbs" $(\mathrm{n}=3)$; and "water-efficient laundry appliances" $(\mathrm{n}=4)$. Most interviewees were highly satisfied with the good performance of HVAC systems: "centralized heating system is efficient" and the "air exchange system keeps the basement cool in summer without air conditioning and keeps the basement warm in winter." Several respondents did express the need for improvements in the HVAC systems in their homes. For example, they wished for a better heating control system, a central air conditioning system, and screen doors on the back of their homes for air circulation. The majority of the interviewees described lighting fixtures as efficient and said the switches worked well, but dimmers or timer switches needed to be added for better efficiency.

Most interviewees responded that the water supply worked well and very efficiently. For example, one respondent appreciated how all toilet units and faucets are water-saving units that function correctly. Yet, some respondents were not satisfied with the performance of efficient faucets or toilets and wanted to replace or had already replaced them with conventional, non-efficient ones. They indicated that higher water pressure was needed in bathrooms and the kitchen and that it took a long time for the water heater to heat water upstairs.

\subsection{Indoor Environmental Quality (IEQ)}

\subsubsection{Overall Satisfaction with IEQ}

Table 9 shows the level of satisfaction with 6 IEQs including temperature, humidity, indoor air quality, daylight, artificial lighting, and acoustic quality. 
Table 9. Level of satisfaction with the indoor environmental quality (IEQ)

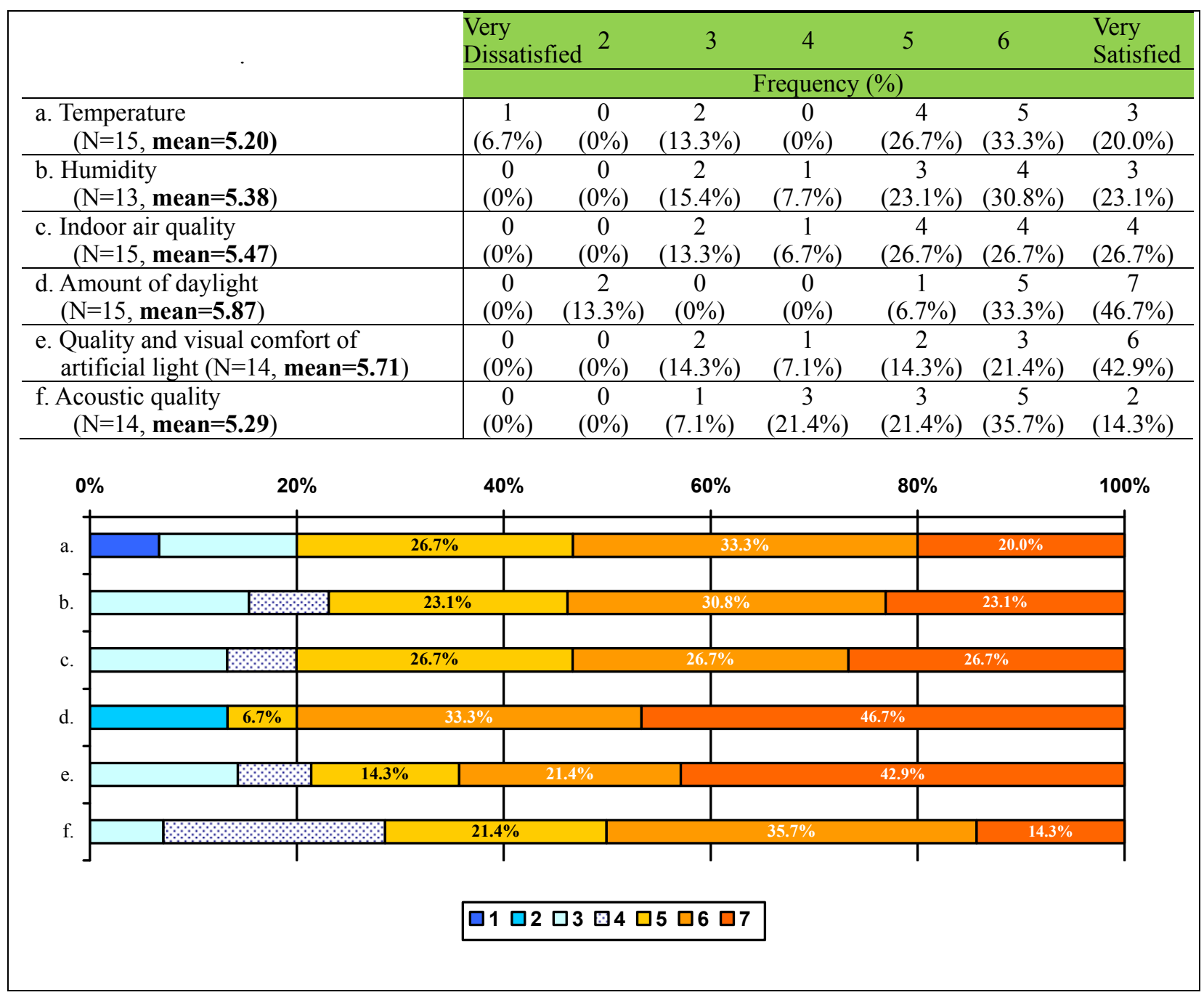

Out of 6 IEQs, the amount of daylight showed the most "very satisfied" (7.0 out of 7.0) ratings with the highest mean score (mean=5.87), followed by quality and visual comfort of artificial lighting (mean=5.71). About $80 \%$ (10 to 12) of the respondents rated as "satisfied" or above (5.0 or above out of 7.0) with temperature, humidity, and air quality, while the ratings of air quality showed the highest mean score (mean=5.37) among those three.

Acoustic quality was rated relatively low (mean $=5.29)$, with the lowest number of "very satisfied" ratings. Ten out of 15 respondents were "satisfied" with the acoustic quality of their homes, but only 2 were "very satisfied" with it. While interview respondents did not express any serious issues or problems in the acoustic quality of their homes during the interviews, the overall ratings were relatively low, which was consistent with many previous POE studies for LEED-certified buildings (e.g., Abbaszadeh et al., 2006; Huizenga et al., 2005; Lee \& Kim, 2008).

\subsubsection{Thermal Comfort}

The indoor temperatures settings in the winter for each case study home are presented in Table 10. The indoor temperatures settings in the winter ranged from $64^{\circ} \mathrm{F}$ to $74^{\circ} \mathrm{F}$. Most interviewees responded that they felt thermally comfortable with the temperatures of their homes because their heating systems, insulation, doors, and windows worked efficiently and nicely provided the appropriate thermal conditions in the winter.

Table 10. Case study homes' indoor temperature setting in the winter

\begin{tabular}{cccccccccccccccc}
\hline Case No. & 1 & 2 & 3 & 4 & 5 & 6 & 7 & 8 & 9 & 10 & 11 & 12 & 13 & 14 & 15 \\
\hline Temperature $(\circ \mathrm{F})$ & 68 & $70-72$ & $65-73$ & $70-71$ & 68 & $70-71$ & 72 & - & 70 & - & $64-70$ & - & 73 & - & 65 \\
\hline
\end{tabular}


On the other hand, in the summer, some respondents expressed thermal discomfort amid hot and humid conditions because all Habitat for Humanity homes in this case study didn't possess a central air conditioning system. Ten out of 15 participating homes used room air conditioner(s) for the living room and/or bedrooms, while 5 homes did not use any room air conditioner. Respondents who did not have any room air conditioner indicated that they just used a big fan $(n=2)$, tried to stay in the basement $(n=2)$, or just opened windows $(n=1)$, when it was very hot in the summer. Some respondents indicated that certain rooms in their homes such as upstairs bedrooms or any rooms with windows in the west walls were very hot in the summer. Overall, the respondents expressed high satisfaction about thermal conditions in the winter while showing lower thermal satisfaction in the summer. Regarding indoor humidity, most interviewees expressed satisfaction with the humidity level of their homes. The majority of the respondents were pretty happy about the easy control of the humidity levels by using room air conditioners or fans.

\subsubsection{Lighting Quality}

Responses about daylight and use of electrical lighting showed definite differences of opinion. Five participants said there was enough daylight because of lots of windows. They indicated that they did not turn on any electrical lighting during the daytime. However, 3 interviewees indicated that their homes were dark because of the lack of daylight, and they needed to turn on electrical lighting during the daytime. Also, a couple of respondents were less satisfied with the east-west orientation of their houses because of too-strong afternoon sun in the summer. According to one interviewee,

"It is dark, and we need more light because other houses are too close and the front of the house is shaded by the overhang." (Case \#8)

Many interviewees expressed that the quality of their electrical lighting was good and calming to the eyes without any glare.

\subsubsection{Air Quality and Ventilation}

Most of the respondents, 8 out of 15, indicated that they have enough cross ventilation due to lots of windows facing each other. There was a stark contrast in respondents' opinions about their built-in air exchanger. Nine out of 15 participants agreed that they have nice indoor air quality because the air exchanger performs well:

"I like the air exchanger because in summer it takes hot air out and brings in cool. In the winter, everything is locked up, so it brings in fresh air without opening windows." (Case \#14)

"Silent fans everywhere that can be switched on. I didn't have to worry about allergies because I have a fresh air system built in; they constantly bring fresh air from outside. ... I love that. All I have to do is... change the air filter." (Case \#3)

On the other hand, 3 respondents indicated that their air exchangers did not perform well, so they unplugged them and did not use them in their homes. The reasons include "filter blows the smoke in," "It makes the basement freezing in the winter," "It brings cool air with the wind," "It's hard to keep the filter clean," and "It was running up my electricity bill."

\subsubsection{Acoustic Qualtiy}

Most interviewees felt comfortable with the acoustic conditions and credited the overall acoustic quality as "good." Interview respondents indicated that they did not experience any serious indoor noise problems except some floors cracking underneath or hearing snoring at night. They were not bothered by any noise from outside when doors and windows were closed, although they can hear some traffic from the street once in a while. One interviewee mentioned the following:

"I have no acoustical issues or problems at all. Walls are pretty thick, and usually noise from outside doesn't bother me... Between rooms, the walls are pretty thin, and sound can be heard between rooms, but it doesn't bother me." (Case \#8) 
Table 11. Level of satisfaction with interior space planning, furnishings, and finishes

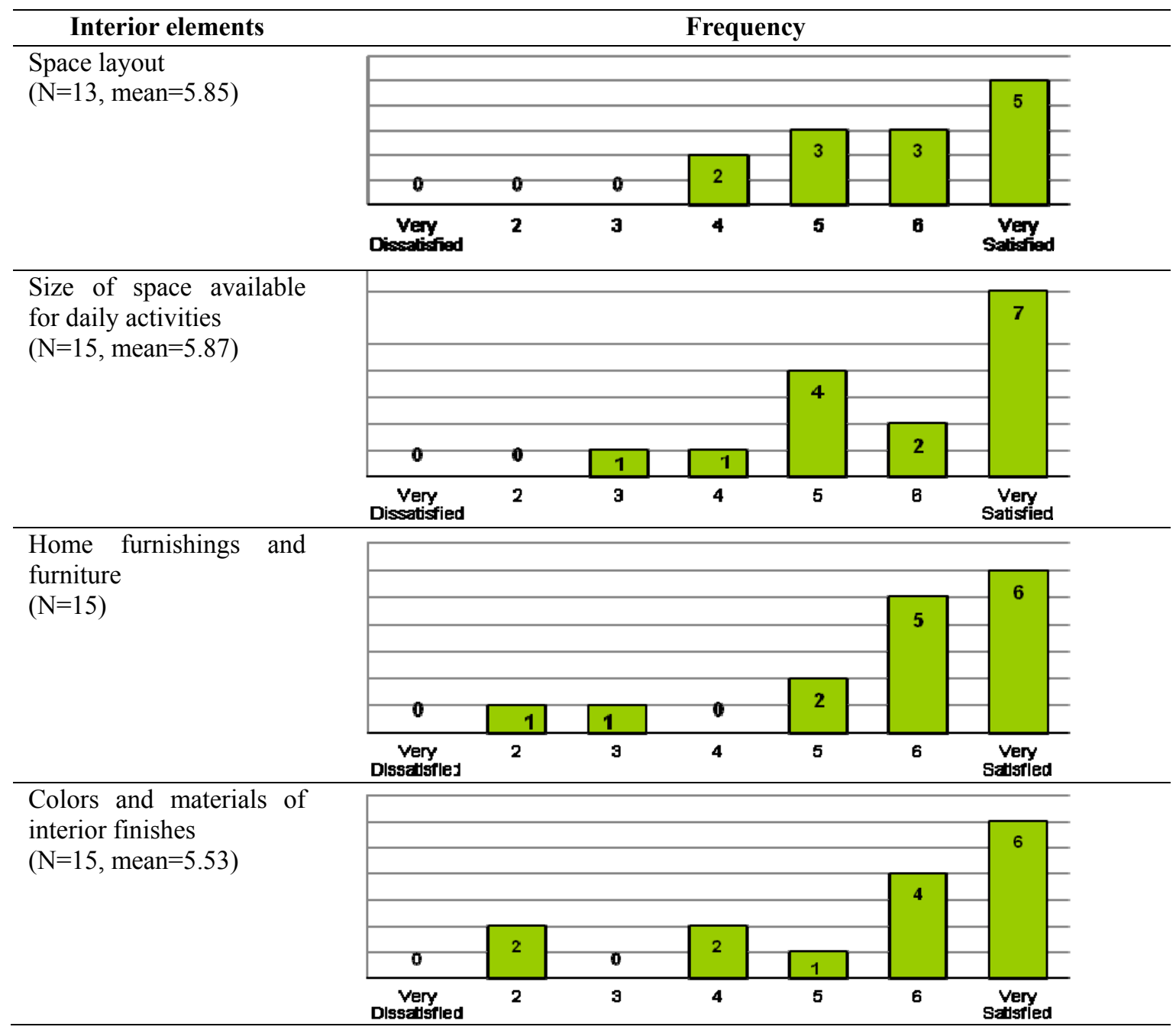

\subsubsection{Interior Space Planning, Furnishings, and Finishes}

Table 11 shows the levels of satisfaction with space layout, size of space available for daily activities, home furnishings and furniture, and colors and materials of interior finishes. All respondents were satisfied with the space layouts. All of them rated their space layouts as 4.0 or higher. Their satisfaction with the size of space available for daily activities was also high. Although more than 10 respondents were highly satisfied with "home furnishings and furniture" and the "colors and materials of interior finishes," some of them were not satisfied with these items at all.

Many interviewees specifically mentioned that they liked the space layout of their homes: "space layout is good to manage," "good connection between rooms," "no unnecessary trip in the indoor space," "I like open planning," "good to have children's own room," "enough closet and storage space," "I like the separate kitchen," and "We have the basement space for children's playing." Yet, three respondents mentioned that they needed more accessible amenities for people with disabilities in their homes such as a ramp from the garage to inside the home.

Five respondents indicated that their room sizes were good, while 2 respondents indicated that they need more space for family gatherings and a larger children's room for accommodating their activities. Most interviewees liked the interior finishes. For example, many respondents indicated the wood flooring was one of the favored finishes because it is less costly for cleaning than carpeted flooring. Some maintenance issues were also mentioned for white walls and shaggy carpet in the heavy-traffic areas. Several homes used a movable vinyl covering or loose carpet swatches over the carpeted floor to keep the carpet clean (see Figure 4). 


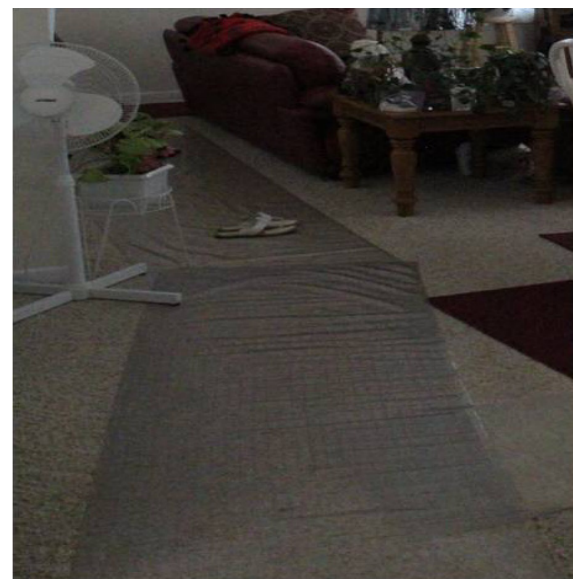

(a)

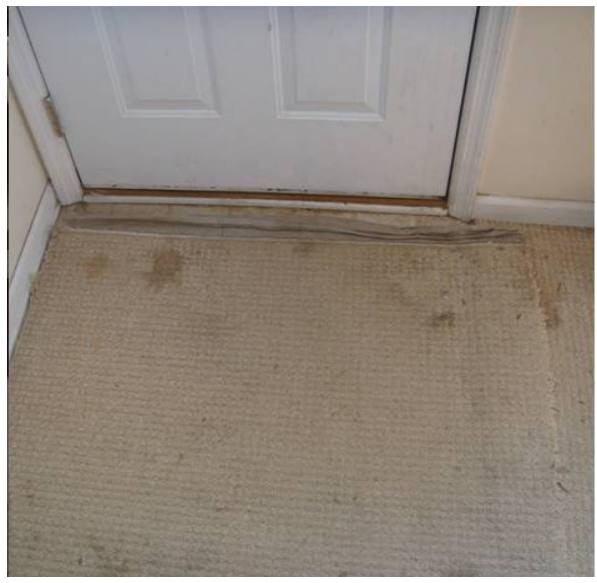

(b)

Figure 4. Examples showing clear vinyl covers (a) and loose carpet piece over the carpeted floor (b)

Some defects in installation, layout, or finishes were mentioned by respondents as less-satisfying features. Examples of defects included uneven surfaces of interior finishes, mismatched doorknobs, wrong switch/power outlet connections, broken closet doors, and awkward countertop locations. One of the respondents stated,

"Habitat for Humanity homes are constructed too fast, and the volunteers are not professional enough and need more supervision." (Case \#4)

\subsection{Perceived Health Impact}

Interviewees were asked whether their family members experienced any changes in their health conditions since moving into their current homes. The responses about the perceived health impacts are presented in Table 12 . Three respondents who had family member(s) with asthma indicated that their asthma symptoms were relieved after moving to the current houses, possibly thanks to good ventilation systems. There were 5 respondents with family member(s) with allergies. One of those respondents indicated that the allergies improved, while 2 respondents indicated no change in their allergies. Two respondents indicated adverse effects after moving because their allergies worsened first and then improved after a few weeks. According to an interviewee,

"I got sick with allergies right after moving into my current home, maybe because of new carpet and the construction dust, but I got better after a few weeks." (Case \#11)

Other positive responses included improvement in coughs, sore throats, or common colds $(n=3)$, fewer ear infections $(\mathrm{n}=1)$, reduced smoking $(\mathrm{n}=1)$, fewer sick days $(\mathrm{n}=2)$, less stress $(\mathrm{n}=2)$, and less anxiety $(\mathrm{n}=2)$. About half of the respondents $(n=6)$ indicated that they were always healthy without any allergies or asthma. Three respondents refused to cite any improvements in their conditions after moving to the current houses, and several said, "I do not know." One interviewee indicated that she did not know whether the change was due to moving, as there could be multiple different influences.

Table 12. Perceived health impact between pre- and post-move

\begin{tabular}{llc}
\hline & \multicolumn{1}{c}{ Participants responses } & Frequency \\
\hline Improvement in & Improvement in asthma symptoms & 3 \\
health condition & Improvement in allergies & 1 \\
& Improvement in coughs or colds & 3 \\
& Fewer sick days & 2 \\
& Fewer ear infections & 1 \\
& Reduced smoking & 1 \\
& Less anxiety & 2 \\
& Less stress & 2 \\
\hline No improvement in & No change in allergies & 2 \\
health condition & Worsened allergy right after moving & 2 \\
& Always healthy (no allergies, no asthma) & 6 \\
& No improvement in any health problem & 3 \\
\hline
\end{tabular}




\subsection{Overall Satisfaction}

\subsubsection{Satisfaction with Home}

Most interview respondents, 12 out of 15 , were highly satisfied with their new homes. Many respondents $(n=6)$ indicated that their living conditions were significantly improved compared to their previous housing. In particular, 6 interview respondents expressed high excitement about owning homes for the first time and living in new homes:

"I'm really, really happy with this house... We enjoy this house. I really appreciate Habitat for Humanity. It is a blessing to have your own house. I don't have any stress of renting anymore. It's my own. My kids and my wife are very happy. It's a big difference to own my house." (Case \#9)

"I love my house, I do, because it's my own, brand new; I can decorate any kind of way I want. ... I always rented with roommates, never owned; so it's my first house that I have ever owned in my name. So, it's awesome." (Case \#3)

\subsubsection{Satisfaction with neighborhood}

Nine out of 15 participants expressed high satisfaction with their neighborhood environments. The major features mentioned by respondents as satisfactory include "good location" $(\mathrm{n}=8)$ such as closeness to schools, bus routes, or grocery stores, "feeling safe" ( $\mathrm{n}=2)$, "quiet" $(\mathrm{n}=2)$, and "good neighbors" $(\mathrm{n}=4)$ :

"Neighborhoods are very quiet, and they haven't had many issues with noise. They are pretty good neighbors. I feel safe." (Case \#8)

"Most satisfying feature of the neighborhood environment is that we are close to a bus route and have a corner store right across the street for food. I have good neighbors." (Case \#3)

Five respondents were less satisfied with their neighborhood conditions. The reasons for dissatisfaction with their neighborhoods include "feeling not safe" $(\mathrm{n}=2)$ because of bad neighborhood conditions such as bars nearby or homeless people around and "unsatisfactory neighbors" $(n=4)$ such as those who made serious noise or troubled the interviewee's family. Three out of 5 less-satisfied respondents indicated that they had security systems in their homes, which made them feel secure. One respondent stated the following:

"I'm not satisfied with the neighbor environment... I am not satisfied with neighbors, ... even my next-door neighbor... They stole from us. So, the biggest reason for dissatisfaction is people and just the environment... There are tattoo shops and bars, and always somebody is moving; lots of homeless people around this area.. So, I don't feel safe always... Though my living condition was improved on the point of home space, ... the environment is not improved... I tried to pick the safest place among the houses as a single mother, but this was the best place I could find at that time." (Case \#7)

Additionally, two interviewees indicated that the playgrounds in their condominiums were not effectively used because they were not appropriate for the ages of kids in that area:

"Less satisfied with the playground, which is quite small for children to play in, and we hope to get more facilities such as monkey bars and baby swings." (Case \#4)

"Playground area was donated...but the set is too immature for the ages of the children in these homes. Many want to donate the structure because they don't use it. Instead, a club house for meetings would be more utilized." (Case \#5)

\subsection{Quality of life}

\subsubsection{Changes in Life.}

Table 12 shows how participants perceived the changes in their lives since moving into the current homes. The results showed that many of the residents (more than $70 \%$ or $80 \%$ ) agreed or strongly agreed with improved living conditions, improved school performance of their children, improved health of family members, and improved quality of life. Respondents rated relatively low on their improvement in social interaction with neighbors, showing that fewer than half of the residents rated "agree" or "strongly agree" with the lowest mean scores (mean=3.46). 
Table 12. Changes in life after moving in

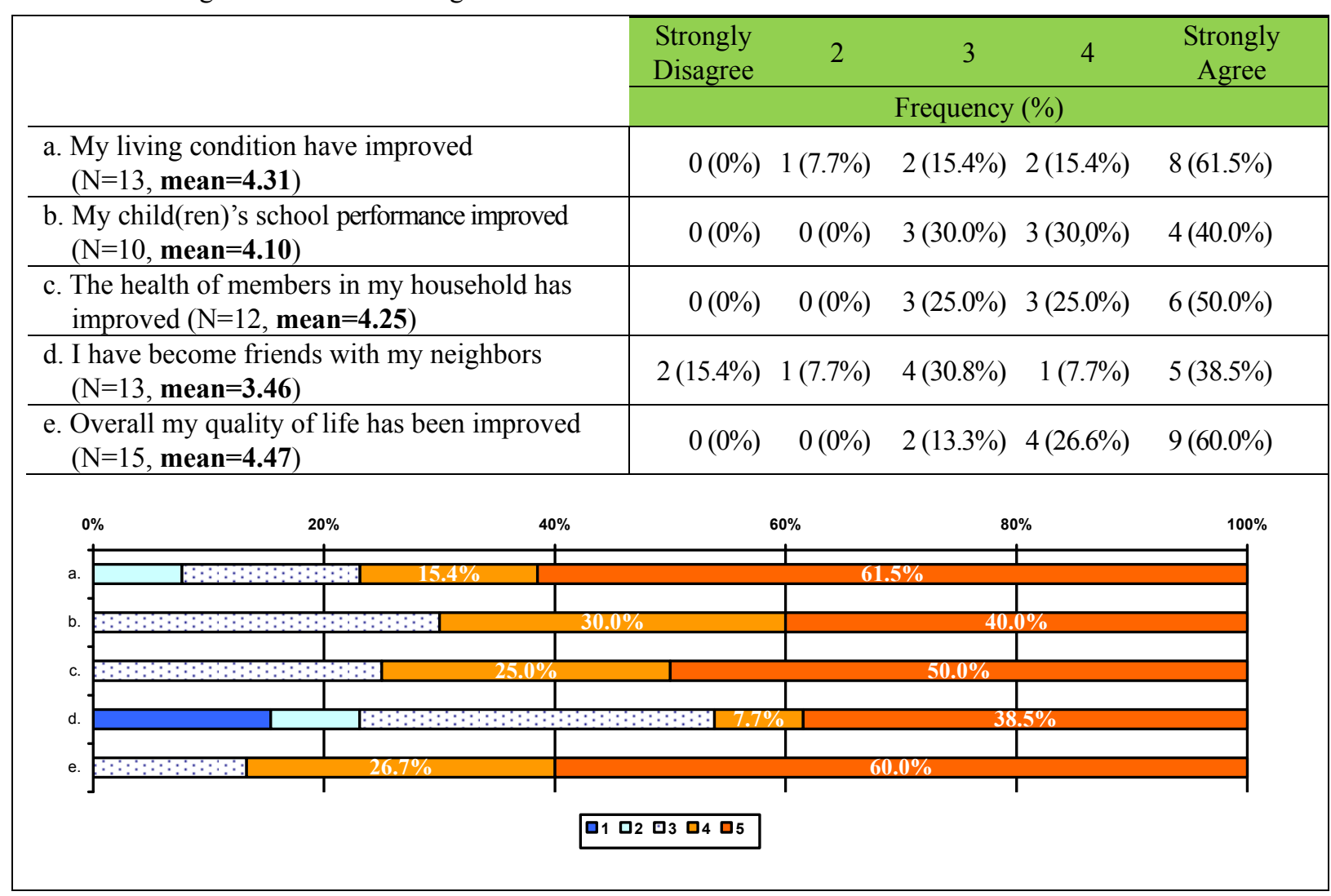

The interview data also revealed that participants' lives changed since moving into their current homes. Three respondents indicated that their family relationships improved. Other changes in their lives includes: "socialize more with friends," "started attending college to get a degree," and "have more confidence after moving in." Many respondents also indicated that their child(ren) changed after moving in. Five respondents mentioned that their children were happier and doing better in school, or feeling more responsible because they have their own space. Two respondents indicated that their children have more confidence and less stress, and another respondent mentioned that the children are more interested in extracurricular activities such as learning Spanish or Taekwondo.

\subsubsection{Perceived Quality of Life}

Table 13 shows interviewees' ratings about their overall perceived quality of life in their current homes. A majority of residents rated their physical well-being, emotional state, ability to handle stress, enjoyment of life, and quality of life as "good" or "excellent."

\subsection{Environmental Attitude \& Behavior}

The most noticeable change in environmental behaviors since moving into their current homes was recycling. Eight respondents indicated that they started recycling for the first time after moving in. They indicated that they had never recycled at all because they did not know what recycling is or how to recycle. According to those respondents,

"I started to pay more attention to my footprint, like starting recycling, which I never did before. And I noticed how much trash I don't have because I do recycle now." (Case \#8)

"I have never recycled in my life...now I recycle everything in sight!...not necessarily to be 'green' but to save money." (Case \#11) 
Table 13. Perceived quality of life in current home

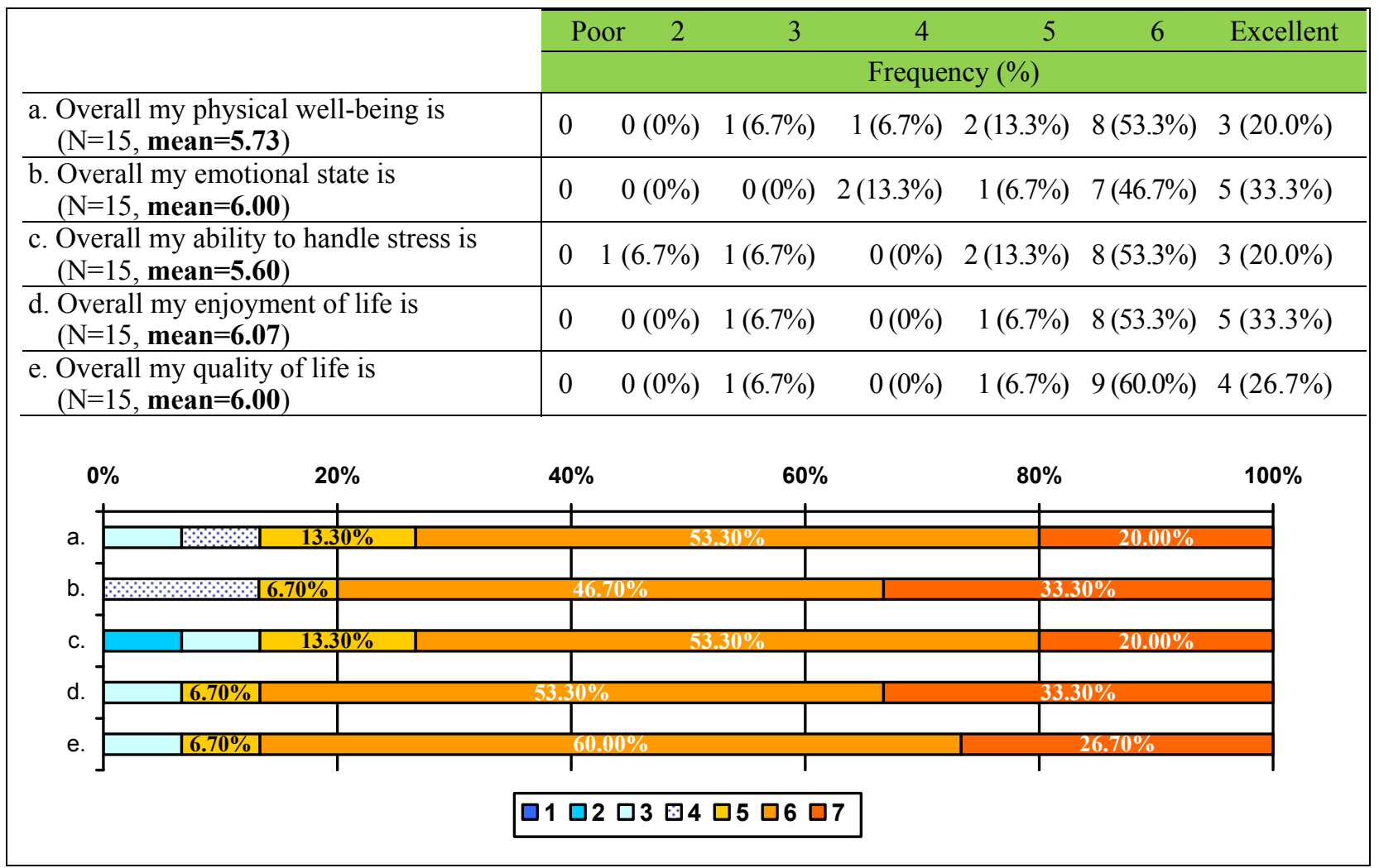

Four respondents indicated that they recycled more than before because it is so convenient to recycle in their current homes. Respondents indicated that the main reasons why they could recycle more in their homes were having incentives and the ease of the recycling system.

One respondent mentioned,

"I do recycle more now. My parents did recycle at their home, but it wasn't as easy as it is here, because now they give us a bin... So now I recycle everything recyclable." (Case \#7)

Another noticeable change in environmental behavior was their efforts in saving energy. Seven respondents indicated that they tried to save more energy by turning off lights or electronic appliances while not in use or replacing light bulbs with energy-efficient ones because they wanted to keep their energy bills low.

"And I always also turn off lights. I never really was aware of it before-how much I can save." (Case \#3)

"Though I might buy a cheaper brand ... I always buy an energy-efficient brand because it does make a difference." (Case \#7)

Other responses about changes in their environmental behaviors included less use of disposable items such as paper towels $(n=2)$, carpooling to work $(n=1)$, and growing tomatoes and peppers $(n=1)$.

Interviewees were asked whether they would recommend green homes to other people, and whether they would prefer moving into a LEED-certified home when they need to move in the future. About half of the respondents stated that it was worth paying the higher initial cost for a LEED-certified home, as they were rewarded by lower utility bills. Most interviewees indicated that they would prefer moving to a LEED-certified home in the future. Respondents also recommended that contractors should have better communication with homeowners to ensure continuing education for proper maintenance and residency in LEED-certified homes.

\section{Discussion}

The present case study focused on the performance of LEED-certified Habitat for Humanity homes by collecting data about (1) energy efficiency, (2) perceived IEQ, (3) perceived health impact, (4) satisfaction with home and neighborhood, (5) quality of life, and (6) environmental behavior using observation, in-depth interviews, and 
survey questionnaires.

The findings showed that most of the case study homes had 30-50\% lower electricity and natural gas bills. All residents were satisfied with the water efficiency and energy savings of electricity and natural gas in their LEED-certified Habitat homes. Although some residents had not noticed any savings on their energy bills, in-depth interviews revealed that residents' family life can affect perceived and actual energy savings.

Regarding IEQs, most participants were very satisfied with the thermal comfort of their homes in the winter due to efficient HVAC systems and good insulation, whereas many participants complained about the absence of central air conditioning for the summer. The respondents were overall satisfied with both the amount of daylight and quality of artificial lighting in their homes, but some respondents indicated that the building orientation and the location of windows should be considered more carefully to bring an appropriate amount of daylight into the interior space. The majority of participants were happy with the indoor air quality because of cross-ventilation and good performance of their air exchangers, but several respondents did not use their air exchanger because they thought it brought cold air into the space during the winter and consumed more energy. Although residents' satisfaction with acoustic quality was rated lowest among IEQs, interviews revealed participants were relatively pleased with acoustic condition of their homes. The majority of participants were satisfied with space layout and size but several respondents wished to have more amenities for people with disabilities, larger bedrooms, and more easily maintained interior finishes in their homes. Participants also thought that more supervision is needed during the construction to reduce defects in the buildings.

The findings revealed positive health effects of LEED-certified homes. All respondents whose family member(s) had asthma noticed that their symptoms had subsided while those with allergies did not show much improvement. Most participants agreed that since moving into their current homes they have experienced improved family relationships, better health conditions, more positive attitudes, better performance of their children, and more confidence in their life. Most participants indicated they had good or excellent physical and emotional status, life enjoyment, and quality of life. Overall satisfaction with their homes were very high although some residents indicated lower satisfaction with their neighbors and the safety of their neighborhood. The major change in their environmental behaviors was their improved efforts on recycling because of convenient recycling systems and the credits given to them.

The major findings of this case study strongly support the positive effects of LEED-certified low-income homes on residents' behavioral, social, and psychological aspects of well-being. These results shed light on the necessity of enhancing green features in low-income houses to improve residential satisfaction and quality of life of low-income families. Thus, there should be stronger support for developing more green Habitat for Humanity homes. Policy makers should understand this necessity and promote incentives or financial support for green low-income home development and supply. More programs that can offer incentives for participation in LEED, green-building certification programs and increase funding opportunities to cover the initial costs of LEED-certified homes for low-income families at both state and local levels should be developed because those efforts will produce long-term economic and environmental benefits. However, as the findings of this study revealed there were some problems in maintaining the green features, building performance, and comfortable home environment, architects, designers, engineers, green building policy makers, and Habitat for Humanity affiliates should pay more attention to the building quality.

This study contributes to the knowledge of human health, indoor environmental quality, and sustainable housing design. Although there is a consensus about the benefits of green homes, few empirical studies examined the actual effects of LEED-certified green homes on residents' health, comfort, and satisfaction. The present study therefore expanded understanding of the benefits to be gained from LEED-certified, low-income homes by providing empirical data and offering fundamental tools for POEs for future studies. Further extensive implementation of POE for LEED-certified homes is suggested to verify results of this study.

\section{Acknowledgments}

This work was financially supported by Institute for Public Policy and Social Research at Michigan State University. I would like to express my gratitude to GreenHome Institute for their help in collecting data from the LEED-certified home residents

\section{References}

Abbaszadeh, S., Zagreus, L., Lehrer, D., \& Huizenga, C (2006). Occupant satisfaction with indoor environmental quality in green buildings. Proceedings of Healthy Buildings, 3, 365-370. Retrieved from https://cloudfront.escholarship.org/dist/prd/content/qt9rf7p4bs/qt9rf7p4bs.pdf?t=lptxax 
Altomonte, S., \& Schiavon, S. (2013). Occupant satisfaction in LEED and non-LEED certified buildings. Building and Environment, 68, 66-76. https://doi.org/10.1016/j.buildenv.2013.06.008

Colton, M. D., MacNaughton, P., Vallarino, J., Kane, J., Bennett-Fripp, M., Spengler, J. D., \& Adamkiewicz, G. (2014). Indoor air quality in green vs conventional multifamily low-income housing. Environmental science \& technology, 48(14), 7833-7841. https://doi.org/10.1021/es501489u

Fowler, K., Rauch, E., Henderson, J., \& Kora, A. (2011). Re-assessing green building performance: A post occupancy evaluation of 22 GSA buildings. Technical Report of Pacific Northwest National Laboratory. Retrieved from https://www.pnnl.gov/main/publications/external/technical_reports/PNNL-19369.pdf

Frontczak, M., Schiavon, S., Goins, J., Arens, E., Zhang, H., \& Wargocki, P. (2012). Quantitative relationships between occupant satisfaction and satisfaction aspects of indoor environ quality and building design. Indoor air, 22(2), 119-131. https://doi.org/10.1111/j.1600-0668.2011.00745.x

Fuerst, F., McAllister, P., Nanda, A., \& Wyatt, P. (2015). Does energy efficiency matter to home-buyers? An investigation of EPC ratings and transaction prices in England. Energy Economics, 48, 145-156. https://doi.org/10.1016/j.eneco.2014.12.012

Garland, E., Steenburgh, E. T., Sanchez, S. H., Geevarughese, A., Bluestone, L., Rothenberg, L., ... Foley, M. (2013). Impact of LEED-certified affordable housing on asthma in the South Bronx. Progress in community health partnerships: research, education, and action, 7(1), 29-37.

Green Home Institute. (2011). Habitat for Humanity commits to LEED and reduces homeowner utilities. Retrieved from https://greenhomeinstitute.org/habitat-for-humanity-commits-to-leed-and-reduces-homeowner-utilities/

GSA. (2011). Green building performance: A Post occupancy evaluation of 22 GSA buildings. Retrieved from https://www.gsa.gov/cdnstatic/Green_Building_Performance2.pdf

Habitat for Humanity of Kent County. (2018). Beyond the home. Retrieved from https://www.habitatkent.org/sustainability/

Habitat for Humanity. (2011). Habitat for Humanity and the Home Depot Foundation partner to repair homes with U.S. military veterans and families. Retrieved from https://www.habitat.org/newsroom/09-26-2011-hfh-and-home-depot-partner

Habitat for Humanity. (2012). Newsletter: Habitat for Humanity of Merced County, Inc. Retrieved from http://www.hfhmerced.org/bulletins/newsletters/habnewsltr_feb_mar_12.pdf

Habitat for Humanity. (2018). Frequently asked questions. Retrieved from https://www.habitat.org/about/faq\#what

Huizenga, C., Zagreus, L., Abbaszadeh, S., Lehrer, D., Goins, J., Hoe, L., \& Arens, E. (2005, November). LEED post-occupancy evaluation: Taking responsibility for the occupants. Proceedings of greenbuild conference. Retrieved from https://www.cbe.berkeley.edu/research/pdf_files/Huizenga_Greenbuild2005.pdf

Huizenga, C., Zagreus, L., Arens, E., \& Lehrer, D. (2003). Measuring indoor environmental quality: a web-based occupant satisfaction survey. Proceedings of greenbuild conference. Retrieved from https://cloudfront.escholarship.org/dist/prd/content/qt8zc5c32z/qt8zc5c32z.pdf?t=lptxz7\&v=lg

Issa, M. H., Rankin, J. H., Attalla, M., \& Christian, A. J. (2011). Absenteeism, performance and occupant satisfaction with the indoor environment of green Toronto schools. Indoor and Built Environment, 20(5), 511-523. https://doi.org/10.1177/1420326X11409114

Jeong, J., Hong, T., Ji, C., Kim, J., Lee, M., \& Jeong, K. (2016). Development of an evaluation process for green and non-green buildings focused on energy performance of G-SEED and LEED. Building and Environment, 105, 172-184. https://doi.org/10.1016/j.buildenv.2016.05.041

Liang, H. H., Chen, C. P., Hwang, R. L., Shih, W. M., Lo, S. C., \& Liao, H. Y. (2014). Satisfaction of occupants toward indoor environment quality of certified green office buildings in Taiwan. Building and Environment, 72, 232-242. https://doi.org/10.1016/j.buildenv.2013.11.007

National Association of Realtors (2018). Realtors and Sustainability. Retrieved from https://www.nar.realtor/research-and-statistics/research-reports/realtors-and-sustainability

Newsham, G. R., Birt, B. J., Arsenault, C., Thompson, A. J. L., Veitch, J. A., Mancini, S., ... Burns, G. J. (2013). Do 'green' buildings have better indoor environments? New evidence. Building Research \& Information, 
41(4), 415-434. https://doi.org/10.1080/09613218.2013.789951

Newsham, G. R., Mancini, S., \& Birt, B. J. (2009). Do LEED-certified buildings save energy? Yes, but.... Energy and Buildings, 41(8), 897-905. https://doi.org/10.1016/j.enbuild.2009.03.014

Newsham, G., Birt, B., Arsenault, C., Thompson, L., Veitch, J., Mancini, S., ... Burns, G. (2012). Do green buildings outperform conventional buildings? Indoor environment and energy performance in North American offices. Ottawa, Canada: Research Report RR-329, National Research Council.

Preiser, W. F. E., Rabinowitz, H. R., \& White, E. T. (1988). Post Occupation Evaluation. NewYork, NY: Van Nostrand Reinhold.

Scofield, J. H. (2013). Efficacy of LEED-certification in reducing energy consumption and greenhouse gas emission for large New York City office buildings. Energy and Buildings, 67, 517-524. https://doi.org/10.1016/j.enbuild.2013.08.032

Scofield, J. H., \& Doane, J. (2018). Energy performance of LEED-certified buildings from 2015 Chicago benchmarking data. Energy and Buildings, 174, 402-413. https://doi.org/10.1016/j.enbuild.2018.06.019

Singh, A., Syal, M., Grady, S. C., \& Korkmaz, S. (2010). Effects of green buildings on employee health and productivity. American journal of public health, 100(9), 1665-1668. https://doi.org/10.2105/AJPH.2009.180687

USGBC. (2015). The Business Case for Green Building. Retrieved from https://www.usgbc.org/articles/business-case-green-building

USGBC. (2018a). LEED for Homes Market Brief. Retrieved from https://www.usgbc.org/advocacy/homes-market-brief

USGBC. (2018b). LEED in Motion: Residential. Retrieved from http://go.usgbc.org/homes

USGBC. (2018c). Benefits of Green Building. Retrieved from https://www.usgbc.org/articles/green-building-facts

Walls, M. (2017). Energy efficiency: Building labels lead to savings. Nature Energy, 2(4), 17055. https://doi.org/10.1038/nenergy.2017.55

Walls, M., Gerarden, T., Palmer, K., \& Bak, X. F. (2017). Is energy efficiency capitalized into home prices? Evidence from three US cities. Journal of Environmental Economics and Management, 82, 104-124. https://doi.org/10.1016/j.jeem.2016.11.006

\section{Copyrights}

Copyright for this article is retained by the author(s), with first publication rights granted to the journal.

This is an open-access article distributed under the terms and conditions of the Creative Commons Attribution license (http://creativecommons.org/licenses/by/4.0/). 